\title{
Effects of Dharma Practices on Psychological Well-Being of the participants Mental Development and Create Intellectual Program of the Palangit Dharma Jakrawan Institute (PDJ) Applying the principles of the Nine Keys Philosophy
}

\author{
Chonnapha Punnanan \\ The independent Researcher \\ chunipha@hotmail.com
}

\begin{abstract}
This Research is Quasi-Experimental Research of the Explanatory Sequential Research Design. The purposes of this research were Effects of Dharma Practices on Psychological Well-Being of the participants Mental Development and Create Intellectual Program of the Palangit Dharma Jakrawan Institute (PDJ) Applying the principles of the Nine Keys Philosophy. The sample group was selected from 60 peoples who applied to join the meditation practice. It was randomize assigned to a control groups of 15 people and Experimental groups of 15 people. The selection criteria for the experimental groups were (1) People who have lowered the Psychological well-being assessment by the Harold J. Dupuy Psychological Well-Being Scale in 1997. (2) The sample groups agreed and voluntarily participated Mental Development and Create Intellectual Program of the Palangjit Dharma Jakrawan Institute (PDJ) Applying the principles of the Nine Keys Philosophy. The data were analyzed by using Descriptive statistics, percentage, mean, standard deviation and t-test. The Research was found that (1) The Pretest of dharma practice control groups and experimental groups have moderate of Psychological Well-Being. (2) The posttest scored for experimental groups were higher control groups at .001 level of significance. (3) The posttest of experimental groups was higher Psychological Well-Being than before the training Mental Development and Create Intellectual program at .001 level of significance
\end{abstract}

Index Terms

Effects of Dharma Practices, Psychological Well-Being, PDJ, Nine Keys Philosophy

Article Received: 10 August 2020, Revised: 25 October 2020, Accepted: 18 November 2020

\section{Introduction}

Mental Health is a component of health. The World Organization refers to mental health as the state of complete physical, mental, social well-being, and relate to the life of the person. According to Jahoda concept mental health is a quality of live, resistance to stress. Which is a basic activity that a person must appreciate your actions and continually decide to take action, Therefore, it will affect the maintenance of mental health in a happy state. In addition, good mental health is an essential part of well-being, adaptation, optimize, and emotional intelligence [1].

Mental Health it reflects the quality of life and the optimize of the environment. such as, life satisfaction and there is not have Psychological distress. In addition, psychological wellbeing can develop from understanding, wisdom, and mental training. Therefore, the religion should be teaching about happiness and how to learn for create happiness in life. Because all the religion is committed to coexistence in peace, and peace can achieve when a person is having good psychological well-being by practicing the mind will affect the physical, healthy, and not suffering from mental illnesses, insomnia, loss of appetite etc. [2]

Psychological well-being will affect for human life in many dimensions such as education, the people who have good psychological well-being be able to successfully in study, career, be motivated to fight various obstacles and success in family life. As for the people who have poor mental health often will have an unstable mood, can't control their emotion, have difficulty adjusting, can't adversity quotient and the realities of life reasonably and effectively. [3]
Ryff say that, is psychological well-being as the satisfaction from achieving success in a person's life assessed by all events that passed through life, psychological well-being is a condition that indicates of positive mental health consist of 6 dimensions were

1. Autonomy refer to the people who can do self-assess according from true and their own standards, be able to withstand social pressures of thoughts and action; able to direct and control behavior from within self.

2. Environment mastery refer to the ability to control the hassle of activities be able to use opportunities that are effective.

3. Positive relation with others refer ability to understand the empathy, ability for love, good relationship, and understanding of giving and receiving interpersonal relationship.

4. Purpose in life refer to having goals in life and being able to set your own direction in life, have a belief that is based in the mind in order to lead a purpose in life, and see the self-esteem and meaning of past life.

5. Self-acceptance refer to the self-awareness and a positive for self-attitude, understanding and self-acceptance in positive and negative, and have good positive about their past.

6. Personal growth refer to ability to open the new experience and recognize the new opportunities for selfimprovement aware of continuous self-development and growth realize for your potential, and there is a change that reflects to self-awareness and self-efficacy. [4] Fisher summary the psychological well-being is mean quality of life, it's the ability to learn, social ability, life satisfaction, 
condition of all aspects of health including the ability to perform their duties. [5]

In the Buddhist principles is view that: physical and mind are closely related, and they cannot be separated. The Medical research was found that: the state of mind influences the immune system because the state of mind is associated with the autonomic nervous system it causes the effects such as, stress, anger is stimulating the autonomic nervous system causing the physical to secrete neuronal chemicals that are connected by immune cells in the bone marrow. In contrast the mind is free from negative emotion such as love, compassion, forgiveness of others. Moreover, the Buddhist principles or psychological principles are all based on the Hedonic perspective which is a positive felling without negative emotion such as the feeling of pleasure, satisfaction. In addition, happiness as a positive mental health is the Eudaimonic perspective of happiness in relation to mental functioning, it is a self-realization that affect life and human potential development which will improve immunity and good psychological well-being. [6]

Adolescence is the age when there is a transition from childhood to adulthood, there is a risk of various problem followed in physical, mental, emotional, and social aspects. [7] Adolescents who live in a single parent's household to face poverty and leave school, resulting in a social problem that follows Adolescence is an important developmental period to become a quality adult. Which the family context is

especially important because adolescents need support in the process of changing personality pattern from family members. [8] The child will have good psychological wellbeing and how well to socially healthy depends on perceptions and experiences, so it is important to a child's perception of their own life satisfaction that is a good psychological well-being.

Mental health problems which are considered influencing people of all genders and ages can be considered as an obstacle in living a happy life. The mental health situation of adolescents aged 15 and over is on the rise. The survey was found that, mental health in this age group was lower than the general population in 2552, 2557 and 2558, if classified by region found that, the northern region had 12.3 percent lower mean mental health score than the general region and the average score of adolescents age 15-24 year has the lowest average score. [9] This mean that adolescents have lower mental health than other adolescents because of rapid physical, economic and social change that together with adolescents are a turning point. There are have physical, mental, and emotional changes. The problem that are found in Thailand were stress. From the report of the Department of mental health regarding the accumulated stress of Thai people found that, suicide is a major problem for Thai society. In each year more than 3,500 peoples successfully commit suicide and according to statistics in 2011, 3,873 Thais died from suicide, representing 6.03 percent per 100,000 people. When analyzing statistics for each age group it was found that Thai adolescents must especially concerned about as adolescents are the age that is coping with problem in life and has to adapt in many ways. In addition, adolescents are not much experience may result in mental health problem. [10]
The practice of Dhamma in Buddhism is interpreted according to the knowledge and experience of the individual. The words that convey or describe Buddhist practices are pray to the Buddha, meditate, compassionate, and keeping the five precepts. When the global change and have stimuli from the environment, the disruption and new technology came in the practice of morality was elevated as a behavior therapy, meditation, intelligence and applying psychological principles. [11] From the review literature was found that, most of the research has led to Dhamma practice to train strength and psychological well-being such as the education of Panida Chonwittayasitikul who study Hardness and Psychological well-being of youth Dhammic Practitioners: A Case Study of the Young Buddhist Association of Thailand Participants, it's a quasiexperimental research. The sample used was Youth aged between 16-24 years of 103 peoples (39 men and 64 women).

Dharma practices take 8 days 7 nights. This research used the strength measure scale from kobasa in 1979 and psychological well-being scale from Harold J.Dupuy in 1977. Dharma practice program used the renunciation using the four foundations of mindfulness. The research was found that, the pretest scores on hardiness and psychological wellbeing of youth dhamma practitioners indicated high level of hardiness and moderate level of psychological well-being. The posttest and the follow-up scores on hardiness of youth dhammic practitioners were higher than its pretest scores at .05 level of significance and have hardiness posttest followup Dharma practice period are not different. The posttest and the follow-up scores $\mathrm{n}$ psychological well-being of youth dhammic practitioners were higher than its pretest scores at .05 level of significance. No differences on those scores were found between the posttest and the follow-up data. [12]

At the same time, the practice of Dharma has been used to improve develop psychological well-being of those who have participated in Dharma practice programs such as the study of Mutita Kongpan.who study Effect of Practice the Dhamma to Psychological Well-Being of Practitioners in the Intensive Meditation Program for the Spiritual Development of the Young Buddhists Association of Thailand Under the Royal Patronage. It's a quasi-experimental research, 250 participants were selected from all dhamma practitioners. The majority of them was females 81.2 percents, 15-29 years old 38 percents, the sample selection criteria were Dharma practitioners with cooperative consent to conduct research without limitation of gender, age, education, occupation. Harold J. Dupuy's 1977 psychological wellbeing Scale was used to measure the mental well-being of participants in Dharma practices. Dharma practice program used the renunciation using the four foundations of mindfulness. The research was found that, the pre-test score on psychological well-being of sample indicated moderate level, the post-test score on psychological well-being of sample was higher than its pre-test scores at 0.05 level of significant. [13]

In addition, the practice of Buddhism must be influence on the Buddhist belief together in order to affect those who participate in the Dharma practice in order to develop their psychological well-being, but if those who participate in dharma practice do not experience and sense of coherence 
then developing of psychological well-being is only a shortterm goal such as research of Darawan Raksat (2557) study about The Effect of Buddhist Characteristics on Psychological Well- Being of Adolescents in Holistic Mind Development for Youth Project of the Young Buddhists Association of Thailand Under Royal Patronage; The Mediating Roles of Sense of Coherence. This research is a correlation research. The sample was used 424 youths participating in the integrated Youth mental development project in 2013 aged 13-22 years. The research was found that, the belief of Religious has direct affect for psychological well-being and Buddhist beliefs has indirect effect psychological well-being through the sense of coherence. As for the Buddhist practice there is a direct effect on psychological well-being and Buddhist practice has indirect effect on psychological well-being through sense of coherence especially sense of coherence is mediators of some variables. [14]

From the review literature, the past of research papers it was found that the most of research used same area scope to study and most of sample groups is youths. Where the Dharma practice program uses the same principles as the four foundations of mindfulness, At the same time was found that, this research will study is different from the past because it studies of the effect of Dharma practice that affects psychological well-being applying the nine keys philosophy, which is a philosophy that has recently been used in academic work. Over the past, nine keys philosophy have been studied whether are dimension of human development, conflict resolution, personal development. In addition, the research of chunipha poedloknimit (2020) study of A Causal Relationship Model of Mental Development and Create Intellectual Prosperity among Ethical Training in Palangjit Dhamma Jakrawan (PDJ) Institution with Nine-Keys Philosophy, the research was found that, the training course for the Mental Development and Create Intellectual Prosperity among Ethical Training have direct effect for participants have more ethical knowledge, followed by ethical attitudes, ethical reasoning and ethical behavior with statistical significance at the .01 level. [15]

For this reason, the researcher is interested in studying the psychological well-being of the partitioners before and after the experiment using by the training course on the development of mental intelligence and applying nine keys philosophy principles from PDJ Institute. However, the programs can use in education institutions, public sector, private sectors who interested in promoting psychological well-being of Thai peoples to be productive and increased emotional intelligence and have the power to fight against obstacles in life better.

\section{: II. Research Objectives}

Objective of this research was study Effects of Dharma Practices on Psychological Well-Being of the participants Mental Development and Create Intellectual Program of the Palangjit Dharma Jakrawan Institute (PDJ) Applying the principles of the Nine Keys Philosophy

\section{Research Methods}

\section{A. Research Design}

This research is a quasi-experimental research study by one group pretest-posttest design to study Effects of Dharma Practices on Psychological Well-Being of the participants Mental Development and Create Intellectual Program of the Palangjit Dharma Jakrawan Institute (PDJ). The independent variable is the program of Dharma practices of the PDJ applying the nine keys philosophy and dependent variable is psychological well-being and using Non-Randomized Control Group Pretest Posttest Design. The control group will receive a general training course is prayer, meditation, walking meditation. For those in the experimental group, the practice of Dharma is integrated with the nine keys philosophy through a program of psychological well-being applying the nine keys philosophies.

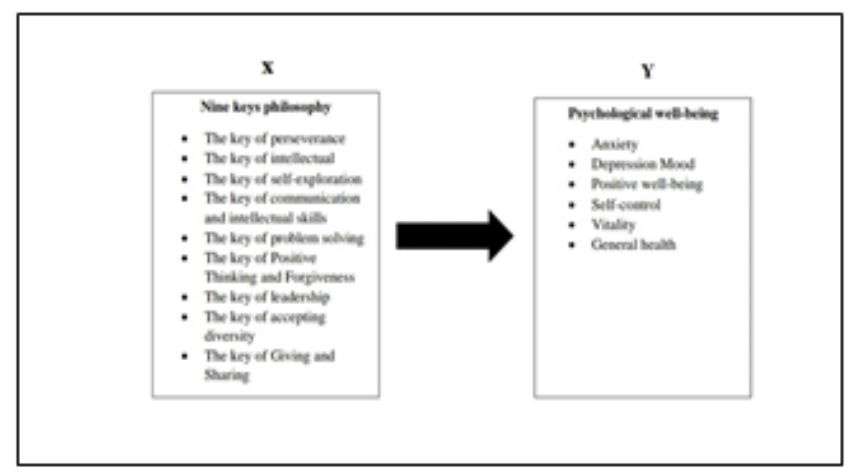

Fig 1 Conceptual Framework

\section{Participants}

Target Population is 60 Dharma practitioners who attended the training course for Mental Development and Create Intellectual Program from 1-9 January 2019. The convenience sample consisted of 30 people who interested to practice Dharma in Mental Development and Create Intellectual Program attended the training from 1-9 January 2019.

\section{Inclusion and Exclusion Criteria}

The inclusion criteria for this study were Dharma practitioners with cooperative consent to conduct research and stay for 9 days of training by requiring all trainees do self-assessment of psychological well-being, and the exclusion criteria were Dharma practitioners who do not practice Dharma for 9 days and do not enter the Mental Development and Create Intellectual Program.

\section{Measures}

The Psychological well-being scales (PGWBS) is widely used Harold J. Dupuy in 1977 based on the theory of Kurt Lewin who believe that the mental behavior is holistic and cannot be view individually. The characteristics of the psychological well-being scale consists of 16 items and divided into different components were

1. anxiety were items 2,5 , and 9

2. depression were items 4,12 , and 16

3. positive well-being were items 1,6 , and 11

4. self-control were items 3,7 , and 13

5. vitality were items 9,14 , and 15

6. general health were items 10 
The Positive questions are a total of 6 question consists of items $1,3,6,9,11,13$, and negative questions are a total of 8 questions consists of item $2,4,5,7,8,10,12$, and 14 . There are two questions that are linear analog scale is items 15 and 16 . The psychological well-being scale was asked about events that happened in the past 1 month. From the part 1 consists of 14 items is Rating scale of 6 level have scored from 0-5 dived into six positive questions, eight negative questions with a full scored of seventy with the following scoring criteria as follows

\begin{tabular}{|c|c|c|c|c|c|c|}
\hline $\begin{array}{c}\text { Rating } \\
\text { scale }\end{array}$ & excellent & good & moderate & low & Very low & never \\
\hline $\begin{array}{c}\text { Positive } \\
\text { question }\end{array}$ & 5 & 4 & 3 & 2 & 1 & 0 \\
\hline $\begin{array}{c}\text { Negative } \\
\text { question }\end{array}$ & 0 & 1 & 2 & 3 & 4 & 5 \\
\hline
\end{tabular}

From the part 2 consists of linear analog scale. The question has scored 0-10 points, 0 means we do not agree, 10 means I agree with that, there are have positive question is 2 items with full score of twenty points. The scoring criteria as follows

73-110 points is mean high levels of psychological wellbeing

61-72 points is mean moderate level of psychological wellbeing

$0-60$ points is mean low levels of psychological well-being

\section{Content Validity}

The psychological well-being was assessed by five experts and have internal consistency Cronbach's alpha coefficient is .90.

\section{Data Collections}

1. Do a letter requesting permission to collect information to the palangjit dhamma jakrawan Institute (PDJ) and explaining the purpose of collecting information to the director of the PDJ.

2. The researcher explains to the program and the purpose of the research to participants and ask for research cooperation in which the practitioner signed their consent to participate in the research.

3. The practitioner perform a psychological well-being assessment before starting the Mental Development and Create Intellectual Program.

4. After nine day of Dharma practice, the participants in the program will complete the assessment again with the psychological well-being is an original assessment.

5. Collect the data that were analyzed for statistical results.

\section{Data Analysis}

In this study, the researcher used the statistics to analyze the data by SPSS for window version 22 and the Paired sample t-test statistic to test the mean difference of the psychological well-being score between pretest and protest.

\section{Results}

Table 1 Test of Normality

\begin{tabular}{|c|c|c|c|}
\hline \multicolumn{4}{|c|}{ Shapiro-Wilk } \\
\hline $\begin{array}{l}\text { PWB } \\
\text { Scale }\end{array}$ & Statistic & df & $\mathbf{P}$ \\
\hline anxiety & .905 & 15 & .115 \\
\hline depression & .578 & 15 & .006 \\
\hline $\begin{array}{l}\text { Positive } \\
\text { well-being }\end{array}$ & .862 & 15 & .026 \\
\hline $\begin{array}{l}\text { Self- } \\
\text { control }\end{array}$ & .898 & 15 & .089 \\
\hline vitality & .835 & 15 & .011 \\
\hline $\begin{array}{l}\text { General } \\
\text { health }\end{array}$ & .884 & 15 & .055 \\
\hline
\end{tabular}

From the Table 1 it was found that statistic test before data analysis in the quasi-experimental research using the Shapiro-Wilk statistic test. Additionally, the statistic test was between .578-.905 and was statistically significant greater than .05 in the most groups. Therefore, it can be concluded that each data group has a normal distribution.

Table 2 Compare the practitioners psychological well-being scale for pretest and posttest

\begin{tabular}{llll}
\multicolumn{4}{c}{ Scale for pretest and posttest } \\
\hline PWB & \multicolumn{3}{c}{ Experimental Group } \\
& $\bar{X}$ & S.D. & P \\
Pre-test & 46.13 & 8.18 & $<.001$ \\
Post-test & 84.00 & 9.20 & \\
${ }^{* * * *} \mathrm{p}<.001$ & &
\end{tabular}

From the table 2, it was found that the comparison of the psychological well-being scores of those participated in the Mental Development and Create Intellectual Program from PDJ pretest and protest found that, mean of pre-test and post-test psychological well-being scores were significant at .001 level. The post-test score mean entered the Mental Development and Create Intellectual Program from PDJ greater than pretest (Mean=84.00).

Table 3 Comparison of the mean psychological well-being scored of the experimental group classified each aspect

\begin{tabular}{|c|c|c|c|c|c|c|}
\hline \multirow[t]{2}{*}{ PWB } & \multicolumn{2}{|c|}{ Pre-test } & \multicolumn{2}{|c|}{ Post-test } & \multirow[b]{2}{*}{$\mathbf{t}$} & \multirow[b]{2}{*}{$\mathbf{P}$} \\
\hline & $\bar{X}$ & $\begin{array}{l}\text { S. } \\
\text { D. }\end{array}$ & $\bar{X}$ & $\begin{array}{l}\text { S. } \\
\text { D. }\end{array}$ & & \\
\hline Anxiety & $\begin{array}{l}49.2 \\
6\end{array}$ & $\begin{array}{l}9.3 \\
6\end{array}$ & $\begin{array}{l}69.7 \\
3\end{array}$ & $\begin{array}{l}5.8 \\
7\end{array}$ & -8.43 & $<.001^{* * * *}$ \\
\hline $\begin{array}{l}\text { Depress } \\
\text { ion }\end{array}$ & $\begin{array}{l}54.4 \\
6\end{array}$ & $\begin{array}{l}5.4 \\
3\end{array}$ & $\begin{array}{l}72.9 \\
3\end{array}$ & $\begin{array}{l}7.2 \\
4\end{array}$ & -12.21 & $<.001^{\text {*** }}$ \\
\hline $\begin{array}{l}\text { Positive } \\
\text { well- } \\
\text { being }\end{array}$ & $\begin{array}{l}55.4 \\
6\end{array}$ & $\begin{array}{l}4.5 \\
4\end{array}$ & $\begin{array}{l}74.0 \\
6\end{array}$ & $\begin{array}{l}4.1 \\
9\end{array}$ & -25.06 & $<.001^{* * * *}$ \\
\hline $\begin{array}{l}\text { Self- } \\
\text { control }\end{array}$ & $\begin{array}{l}54.2 \\
0\end{array}$ & $\begin{array}{l}7.0 \\
4\end{array}$ & $\begin{array}{l}73.1 \\
3\end{array}$ & $\begin{array}{l}5.8 \\
0\end{array}$ & -11.71 & $<.001^{\text {*** }}$ \\
\hline Vitality & $\begin{array}{l}53.8 \\
6\end{array}$ & $\begin{array}{l}5.2 \\
2\end{array}$ & $\begin{array}{l}72.9 \\
3\end{array}$ & $\begin{array}{l}4.8 \\
3\end{array}$ & -15.23 & $<.001^{* * * *}$ \\
\hline $\begin{array}{l}\text { General } \\
\text { health }\end{array}$ & $\begin{array}{l}54.7 \\
3\end{array}$ & $\begin{array}{l}5.6 \\
5\end{array}$ & $\begin{array}{l}75.7 \\
3\end{array}$ & $\begin{array}{l}8.1 \\
1\end{array}$ & -9.47 & $<.001^{\text {*** }}$ \\
\hline
\end{tabular}


From table 3 it was found that mean score and overall psychological well-being of the pre-test and post-test sample were significant at .001 level.

In addition, when interview the key informants the participated in the Dharma practice Mental Development and Create Intellectual Program from PDJ applying the nine keys philosophy principles was found that, the participants have healthier because being with nature, and without external stimuli to disturb as an interview

"Feeling physically stronger. In the past my physical is frequent discomfort. But after coming to practice Dhamma It's much stronger. "

"I feel don't have anything to disturb, being with new friend, learned through new activities and the Dharma practice is not boring"

As the same time, the participants say that the Dharma practices helps to learn how to control the emotion, selfexploration, self-awareness, and knower how to use reason rather than emotion as an interview

"In the past if I have feeling upset, angry, and speak without thinking. But when I come to Dharma practice program, I feel that I can control my emotion and will thinking before doing"

"if I am not satisfied, I just say it out. Do not care what other people think. But after I came to Dharma practice, I have self-regulation and always thought that what would have been said to other people",

In addition, was found that, the key informants after came to Dharma practice their have self-esteem, not think negatively, and interact with other more than ever as an interview

"Before came to Dharma practice I like to keep myself silent and worthless. But after Dharma practice I felt myself able to do many things. See the aptitude of oneself and other and valuable"

"I don't like many people because I feel chaotic, like to do something alone but never succeeded. But when I come to Dharma practice, I feel it incredibly good when doing activities with friends and have new friend to conversation more"

\section{Discussions}

From the research result was found that, the participants in the Mental Development and Create Intellectual Program applying nine keys philosophy from PDJ the experiment had mean score of 46.13. But when the participants entered the dharma practice program for nine days found that, the experimental group had a mean score of 84.0 and have significant at .001 level. However, the dharma practice in the Mental Development and Create Intellectual Program applying nine keys philosophy from PDJ have a greater psychological well-being. The aspects with the highest mean score were general health $($ Mean=75.73), followed by positive well-being (Mean=74.06), self-control (Mean=73.13), depression (Mean=72.93), and anxiety (Mean=69.73). This research was congruence with muthita khongpun study of effect of Practice the Dhamma to Psychological Well-Being of Practitioners in the Intensive Meditation Program for the Spiritual Development of the Young Buddhists Association of Thailand Under the Royal Patronage. The research was found that, the psychological well-being scores of the participants pretest and posttest were significant at .001 level.

In addition, the participants in the Dharma practice Mental Development and Create Intellectual Program there will be eudinomics happiness and psychological well-being because most of them have self-esteem, self-reliance, and have Positive relationships with other, including management of the environment that occurs in their own minds such as selfcontrol. Therefore, the program focuses on the individual to achieve his own goal and teach people to have selfawareness and self-assessments for their internal emotion related to quality of life and emphasize the happiness and psychological well-being of the participants by raising their positive emotions without negative emotions. This research was congruence with McDowell say that: The psychological well-being is eudinomics happiness. With an emphasis on emotions, felling that a person has purpose in life. [16]

\section{Recommendations}

\section{A. Recommendations for Practices}

1 This study was only one experimental group. Therefore, should be applied nine keys philosophy to other groups.

2 The research was found that, for anxiety variable after the experimental was mean score lower than others. Therefore, should be test it in a correlational research model to see the nine keys philosophy which the keys are to influencing anxiety and make Dharma practice more effective

\section{B. Recommendations for Further Research}

This research study the participants in the dharma practice in the Mental Development and Create Intellectual Program from PDJ. The limitation in this research are a diverse group of samples. The researcher attempted to equalize the sample group to reduce the extraneous variable. The further research should study a larger sample and need to define a specific sample group including follow-up to be conducted for determine if the program is effective in the short or long term to develop appropriate programs.

\section{Conclusion}

Research study the effects of dharma practices on psychological well-Being of the participants mental development and create Intellectual Program of the Palangjit Dharma Jakrawan Institute (PDJ) Applying the principles of the Nine Keys Philosophy found that, in quantitative research which is quasi-experimental research the participants in program had improved the psychological well-being. The participants who come to practice dharma Mental Development and Create Intellectual Program applying nine keys philosophy from PDJ course there was a better psychological well-being than practice without applying the nine keys philosophy. From interview the key informants after participating in the program it was found that participants in dharma practice have positive emotion, self-control, self-esteem, healthier, and have better in quality of life 


\section{References}

[1] Saranya Chanchusakarn, "Causal Factors of Psychology well-being Growth of student teacher During Professional teaching Practice", Degree of Doctor philosophy program, Faculty of Education, Chulalongkorn University.

[2] Pennapa Supcharoen, "Religion and health in Buddhism brings good health", Bangkok: War Veterans Organization Publishing, 1997.

[3] Ibitoye, O., Sanuade, O., Adebowale, A. \& Ayeni, O., "Psychological well-being of the Elderly in Nigeria", The Nigerian Journal of Sociology and Anthropology, Vol.12, pp. 4-85, 2014.

[4] Ryff, Carol D., "Happiness is everything or is it? Explorations on the meaning of Psychological Well-being", Journal of Personality and Psychology, Vol.57, no.6, pp. 1069-1081, 1989.

[5] Fisher, A. G., "Functional measure part 1: What is function, what should we ensure, and how should we measure it?.", The American Journal of Occupation Therapy, Vol. 46, no. 5, pp. 183-185, 1992.

[6] Nina Tamminena, Jaakko Reinikainenb, Kaija Appelqvist-Schmidlechnerc, Katja Borodulinb.d,Tomi Mäki-Opase, Pia Solina, "Associations of physical activity with positive mental health A populationbased", Journal of Mental Health and Physical Activity, Vol. 18, pp.1-8, 2020.

[7] Sackss V, Moore KA, Shaw A, Cooper PM. The family environment and adolescent well-being. Child Trends. 2014;1-12.

[8] Ryff CD, Singer B, "Psychological wellbeing: Meaning, measurement, and Implications for psychotherapy research", Psychotherapy and Psychosomatics, Vol.65, no.1, pp. 14-23, 1996.

[9] National Statistical Office, "Thai Mental Health (Happiness)", Retrieved from: http://service.nso.go.th/nso/nsopublish/the mes/files/mental-

healthm_aug_58.pdf, 2015

[10] Thawee Tang Seree, "Department of Mental Health Ung! Stressful school age accumulates suicide 170 people a year, Retrieved on 25th September 2020, from https://www.thairath.co.th/content/289132, 2017.

[11] Ornampai Samkhunthod, Phra Maha Somboon Wuthikaro, Watcharaphong Chumduang, "An Interpretation of Dhamma Practice in Theravada Buddhism", Vol. 1 no.2, pp. 1-12, 2017.

[12] Panida Chonwitayasitthikul, "Hardness and Psychological well-being of youth Dhammic Practitioners: A Case Study of the Young Buddist Association of Thailand Participants", Thesis Degree of Master, Department of psychology, Chulalongkorn University, 2548.

[13] Muthita Khongpun, "Effect of Practice the Dhamma to Psychological Well-Being of Practitioners in the Intensive Meditation Program for the Spiritual Development of the Young Buddhists Association of Thailand Under the Royal Patronage", Thesis Degree of Master, Department of Medicine, Chulalongkorn University, 2008.

[14] Darawan Raksat, "The Effect of Buddhist Characteristics on Psychological WellBeing of Adolescents in Holistic Mind Development for Youth Project of the Young Buddhists Association of Thailand Under Royal Patronage; The Mediating Roles of Sense of Coherence", Thesis Degree of Department of Education in Developmental Psychology, Srinakharinwirot University, 2014.

[15] Chunipha Poedloknimit, "A Causal Relationship Model of Mental Development and Create Intellectual Prosperity among Ethical Training in Palangjit Dhamma Jakrawan (PDJ) Institution with Nine-Keys Philosophy", Journal of Solid-State Technology, Vol.63, no.2, pp. 1576-1581, 2020. 
[16] McDowell, I., "Measures of self-perceived well-being", Journal of Psychosomatic Research, vol.69, pp. 69-79, 2010 